\title{
O que mães pensam sobre seus filhos em três regiões distintas do Estado de Santa Catarina
}

\author{
What mothers think on their children in three distinct regions \\ in Santa Catarina State
}

\author{
Josielly Pinheiro Westphal ${ }^{[a]}$, Viviane Vieira ${ }^{[b]}$, Mauro Luís Vieira ${ }^{[\mathrm{c}]}$, Alessandra Bonassoli Prado ${ }^{[\mathrm{d}]}$ \\ [a] Graduanda do Curso de Psicologia da Universidade Federal de Santa Catarina (UFSC), Florianópolis, SC - Brasil. \\ [b] Psicóloga formada pela Universidade Federal de Santa Catarina, (UFSC), Florianópolis, SC - Brasil, e-mail: vivianepsicoufsc@gmail.com \\ [c] Doutor em Psicologia, professor associado do Departamento de Psicologia da Universidade Federal de Santa Catarina (UFSC), \\ Florianópolis, SC - Brasil, e-mail: maurolvieira@gmail.com \\ [d] Mestre em Psicologia e Doutoranda do Programa de Pós-Graduação em Psicologia Experimental, Universidade de São Paulo \\ (USP), São Paulo, SP - Brasil.
}

\section{Resumo}

Diferentes questões do desenvolvimento são solucionadas de formas distintas em contextos variados, especialmente no que se refere aos valores, crenças, ideias e práticas parentais. O presente estudo teve como objetivo investigar valores, crenças e práticas parentais de mães na criação de seus filhos no Estado de Santa Catarina. Foram entrevistadas 150 mães residentes em três contextos com diferentes índices de urbanização: capital, interior leste e interior oeste. Foram investigadas práticas parentais durante o primeiro ano de vida da criança, metas de socialização e alocentrismo familiar. Para a análise dos dados, foram utilizadas análises descritivas, cálculos de comparação entre médias (teste t), correlação (Pearson) e análise de variância (ANOVA). Os resultados indicaram a presença do modelo cultural autônomo-relacional em todos os contextos estudados, porém de forma distinta. Em todos os contextos, houve correlação positiva e significativa entre a dimensão alocêntrica e metas relacionais, indicando que quanto mais as mães descrevem proximidade com a família, mais estabelecem metas de socialização relacionais para os filhos. Os resultados encontrados podem auxiliar no delineamento de um modelo cultural de parentalidade do contexto brasileiro, indicando para um predomínio de um modelo cultural autônomo-relacional em Santa Catarina. Contudo, esse modelo não é homogêneo, pois apresenta diferentes configurações dependendo do contexto sociocultural.

Palavras-chave: Crenças sobre práticas parentais. Metas de socialização. Alocentrismo familiar. 


\begin{abstract}
Various issues about development are solved by different ways in distinct contexts, especially regarding values, beliefs, ideas and parenting practices. This study had as purpose to investigate values, beliefs and parenting practices of mothers in the rearing of their children in Santa Catarina State. In total, the authors interviewed 150 mothers living in three contexts with different levels of urbanization: State's capital, east region and west region. Questions on parenting practices, goals of socialization and family alocentrism were investigated. For data analysis, descriptive analysis, calculation of comparison between means ( $t$ test), correlation (Pearson) and analysis of variance (ANOVA) were used. The results indicated the presence of cultural self-relational model in all contexts studied, but in different ways. In all contexts, there were positive and significant correlation between the alocentrism and relational goals, indicating that the more the mothers describe proximity to the family, the more they show relational socialization goals for their children. In conclusion, the found results may help in understanding cultural model of parenting in the Brazilian context, indicating a predominance of a self-relational cultural model in Santa Catarina. However, this model is not homogeneous, because it shows different structures in relation to specific sociocultural contexts.
\end{abstract}

Keywords: Beliefs about parenting practices. Socialization goals. Familiar allocentrism.

\section{Introdução}

Uma das tendências modernas da Psicologia (Vieira \& Prado, 2004) é compreender o desenvolvimento infantil como um processo resultante da interação entre o biológico e o cultural, em que características específicas da espécie (como imaturidade prolongada dos bebês humanos e sua dependência de adultos, alto investimento parental) interagem com as do ambiente cultural em que o ser humano está inserido. Isso implica a importância de explicar as variações desse ambiente cultural que irão repercutir na maneira como as crianças se desenvolvem em cada contexto.

As crianças, quando nascem, já se deparam com ambientes culturalmente organizados, em que adultos já possuem crenças, expectativas e representações e atividades mediadas pelos instrumentos desta cultura (Ruela \& Seidl de Moura, 2007). As crenças são definidas como conjuntos organizados de ideias que estão implícitos na atividade cotidiana e nos julgamentos, escolhas e decisões que os cuidadores tomam, agindo como modelos para as práticas parentais (Harkness \& Super, 1996). Crenças e práticas sobre cuidado infantil são partes do "Nicho de Desenvolvimento", um sistema composto por três subsistemas: ambiente físico e social (tipo de moradia, tipo de organização social da família); costumes e práticas de cuidado compartilhadas e estabelecidas cultural e historicamente (a noção de infância, relações entre gerações); a psicologia dos cuidadores ou etnoteorias parentais (crenças e expectativas de mães em relação a seus filhos) (Harkness \& Super, 1996). Esses três subsistemas influenciam-se e são influenciados mutuamente.

Os pais norteiam seu comportamento na relação com os filhos levando em conta as ideias a respeito de como devem tratar seus filhos, aquilo que acham certo ou errado, comportamentos que são socialmente aceitos ou não, entre outros fatores (Kobarg, 2006). O papel da crença e sua importância, particularmente para o comportamento dos pais, vêm sendo extensamente pesquisados (Goodnow \& Collins, 1990; Harkness \& Super, 1996). Esses últimos autores salientam que as crenças subsidiam o comportamento do individuo, são mais implícitas que explícitas e estão ligadas ao comportamento mesmo sem a mediação de se decidir fazê-lo conscientemente. Há certo consenso de que essas cognições atuam como mediadores, influenciando práticas de cuidado e comportamentos parentais. Esses acabam tendo efeitos diversos sobre o comportamento das crianças e o seu desenvolvimento (Ribas, Seidl de Moura \& Bornstein, 2003). Contudo, não se pode deduzir que as crenças parentais tenham efeitos diretos nas práticas de cuidado parentais, nem que essas práticas tenham efeitos diretos no desenvolvimento infantil. Nem sempre o que as pessoas pensam corresponde ao que fazem, ou seja, as atitudes nem sempre correspondem ao comportamento. 
Um estudo brasileiro realizado por Ruela e Seidl de Moura (2007) teve como objetivo investigar o ambiente físico e social de crianças de uma comunidade rural, analisar algumas ideias, concepções e práticas de suas mães e o que elas desejam para o futuro de seus filhos, como uma tentativa de caracterizar um nicho de desenvolvimento rural brasileiro. Os instrumentos utilizados incluíram a observação naturalística, que teve como meta investigar o comportamento da díade mãe-bebê em sua residência no contexto rural; o diário de campo, que abarcou a descrição das atividades realizadas durante a observação e buscou captar a rotina da mãe com seu filho; e o Inventário do Nicho de Desenvolvimento, para registro de algumas informações. Seis mães foram observadas com seus bebês em suas casas, e preencheram um inventário especifico. Os resultados apontam que o modo como as mães cuidam de seus bebês (ou o que acreditam como o modo adequado de cuidado) tem implicações também sobre as metas de socialização que elas têm para seus filhos e os conhecimentos sobre desenvolvimento infantil.

Alguns estudos realizados na região Sul do País, mais especificamente do Estado de Santa Catarina, foram desenvolvidos com o objetivo de identificar dimensões de crenças sobre práticas (Kobarg, 2006; Piovanotti, 2007). Resultados dessas pesquisas demonstraram que as mães urbanas de alta escolaridade valorizam principalmente a dimensão de práticas de estimulação, caracterizada por proporcionar à criança diferentes tipos de estimulação, tais como interações diáticas e grupais, estimulação com brinquedos, por meio da linguagem, cognição, ente outros. Já as mães com baixo índice de escolaridade e também aquelas do interior, parecem valorizar mais a categoria de práticas de apresentação apropriada da criança em público, como o bom comportamento e higiene.

Por outrolado, as etnoteorias parentais, que são consideradas ideias organizadas e compartilhadas pelos membros de um grupo cultural - geralmente implícitas -, consideradas como verdadeiras e traduzidas em práticas (Cole, 1998; Harkness, 2001; Suizzo, 2002), fazem parte do contexto cultural e social. Três modelos culturais, mais especificamente, têm sido identificados e estudados em função de seus impactos nos processos de socialização e desenvolvimento da criança, a saber:

a) orientação cultural independente, individualista ou autônoma; b) interdependente, sociocêntrica ou relacional (Keller, Borke, Yovsi, Lohaus \& Jensen, 2005; Keller et al., 2004);

c) autônomo-relacional (Kagitçibasi, 2005). Porém, é preciso explicitar que tais orientações representam prioridades idealizadas culturalmente, o que não restringe a existência de outros tipos de orientações, combinações entre eles, além de variações intraculturais e interindividuais.

Os modelos culturais de independência e interdependência foram primeiramente descritos na literatura. O tipo de orientação independente refere-se à construção do self como único e distinto, sendo priorizadas metas pessoais e concentrandose nas necessidades e direitos do indivíduo. Nesse modelo predominam as dimensões de autonomia e separação, características de sociedades urbanas pós-industriais com alto índice de escolaridade. $\mathrm{O}$ modelo de interdependência, por sua vez, concebe o self como fundamentalmente conectado aos demais membros do grupo em que está inserido, sendo priorizadas metas grupais e a focalização de papéis sociais, deveres e obrigações. Nesse tipo de orientação predominam as dimensões de heteronomia e relação, características de ambientes rurais baseados em economia de subsistência (Keller et al., 2005).

O terceiro modelo, proposto por Kagitçibasi (2005), denominado autônomo-relacional, compreende características combinadas de ambos os modelos anteriores. Esse tipo de orientação cultural engloba autonomia e relação, em que o selfé definido como autônomo quanto à sua ação e relacional quanto à proximidade interpessoal. Ele é característico de famílias de classe média, urbana e escolarizada em sociedades tradicionalmente interdependentes.

Diante do pressuposto de que o desenvolvimento infantil é o resultado do processo de interação entre aspectos biológicos do indivíduo e características específicas do ambiente cultural em que ele se insere, verifica-se a necessidade de estudos que investiguem as etnoteorias parentais nos diferentes contextos de desenvolvimento e nas mais diversas culturas. Inúmeros estudos a respeito da parentalidade centram-se em países norte-americanos e europeus; assim, constata-se a necessidade de estudos brasileiros que possam contribuir com a literatura existente, complementando os resultados de estudos já realizados. 
Dessa forma, o objetivo da presente pesquisa foi caracterizar as práticas de mães de três diferentes contextos catarinenses durante o primeiro ano de vida da criança, investigar as metas de socialização que elas possuem para seus filhos de até 3 anos de idade e verificar o grau de alocentrismo familiar dessas mães.

\section{Método}

\section{Participantes}

Participaram desta pesquisa 150 mães, distribuídas em grupos de 50 residentes para cada um dos três diferentes contextos: Florianópolis (capital), cidades de Corupá e Schroeder (interior leste) e Guaraciaba (interior oeste). Elas deveriam ter no mínimo 20 anos de idade, com pelo menos um filho com idade entre 0 e 6 anos.

A amostra do contexto capital é composta por mães com idade entre 21 e 49 anos $(\mathrm{M}=32,14)$, com número de filhos entre um e quatro. A maioria delas tinha uma criança $(n=30)$ no período da coleta dos dados. Grande parte dessas mães é casada ou vive em união estável ( $n=42)$, com composição familiar nuclear $(\mathrm{n}=37)$, é católica $(\mathrm{n}=26)$, tem trabalho remunerado $(\mathrm{n}=39)$, foi criada na zona urbana $(n=42)$, tem escolaridade superior $(n=36)$ e tem renda mensal familiar acima de $\mathrm{R} \$ 2.000(\mathrm{n}=35)$.

Já no contexto interior leste, a amostra é composta por mães com idades entre 21 e 38 anos $(M=29,16)$, com total de filhos entre um e quatro, sendo que a maioria tinha um $(\mathrm{n}=28)$ ou dois filhos $(\mathrm{n}=17)$ durante a coleta dos dados. A maioria dessas mães $(\mathrm{n}=47)$ é casada ou vive em união estável, com composição familiar nuclear ( $\mathrm{n}=$ 44), é católica $(\mathrm{n}=33)$, foi criada na zona rural ( $\mathrm{n}=$ $28)$, tem trabalho remunerado $(n=42)$, escolaridade entre médio completo e superior incompleto $(\mathrm{n}=$ 27) e tem renda mensal familiar entre de $R \$ 301 \mathrm{e}$ $\mathrm{R} \$ 1.300(\mathrm{n}=35)$.

Por último, no contexto interior oeste, a amostra é composta por mães com idade entre 20 e 43 anos $(M=29,80)$, total de filhos entre um e cinco, sendo que a maioria tinha um $(\mathrm{n}=15)$ ou dois filhos $(\mathrm{n}=21)$ na época da coleta dos dados. A maior parte dessas mães é casada ou vive em união estável ( $n=47$ ), com composição familiar nuclear ( $\mathrm{n}=41)$, é católica $(\mathrm{n}=44)$, não trabalha $(\mathrm{n}=33)$, foi criada na zona rural $(n=34)$, tem escolaridade até ensino fundamental completo $(\mathrm{n}=32)$ e tem renda mensal familiar de até $\mathrm{R} \$ 1.000(\mathrm{n}=34)$.

\section{Contextos do estudo}

O contexto da capital situa-se no litoral de Santa Catarina, em Florianópolis. De colonização açoriana, a cidade tem como principais atividades econômicas o turismo e o comércio, destacando-se também como polo tecnológico no Estado, contando com 396.723 habitantes (Instituto Brasileiro de Geografia e Estatística [IBGE], 2006). Esse contexto tem um índice de urbanização considerado alto.

O contexto do interior leste contou com a participação de duas cidades no interior do Estado, Corupá e Schroeder, agrupadas para fins de coleta de dados em um único contexto por compartilharem características semelhantes. Corupá é um município de colonização alemã, italiana e polonesa e possuía população estimada de 12.758 habitantes em 2007. Segundo dados do Governo do Estado de Santa Catarina (2006), o comércio e a indústria são responsáveis por mais da metade da renda do município, que é o maior produtor de banana do Estado.

O município de Schroeder possui 12.776 habitantes (IBGE, 2006) e também é de colonização alemã. A economia do município gira em torno da agropecuária (Santa Catarina, 2006). No contexto do interior, o índice de urbanização está em desenvolvimento, sendo que há uma proximidade territorial com os polos da indústria metal-mecânica de Santa Catarina (Joinville e Jaraguá do Sul).

Por último, o contexto denominado interior oeste situa-se no extremo oeste de Santa Catarina, na cidade de Guaraciaba. De colonização alemã e italiana, com 10.604 habitantes, sua atividade principal é a agropecuária (Santa Catarina, 2006). Nesse contexto, o índice de urbanização é considerado baixo, predominando as áreas destinadas a lavouras e pastagens.

\section{Instrumentos}

Para a realização a coleta dos dados, foram utilizados os seguintes instrumentos: 
a) Escala de Práticas Parentais: elaborada por Keller et al. (2006), foi traduzida e adaptada para o português pelo grupo de pesquisa Interação Social e Desenvolvimento, coordenado pela professora Maria Lúcia Seidl de Moura, do Instituto de Psicologia da Universidade Estadual do Rio de Janeiro (UERJ). Consiste numa escala tipo Likert de cinco pontos (de $1=$ concordo nem um pouco até $5=$ concordo completamente), contendo dez afirmativas para investigar crenças sobre a maneira de cuidar de bebês ou crianças pequenas de até 1 ano de idade. A escala é formada por duas dimensões:

- práticas interdependentes/relacionais, que contêm itens que enfatizam o contato corporal e a satisfação imediata das necessidades físicas (por exemplo, se é importante embalar um bebê que chora para consolá-lo);

- práticas independentes/autônomas, que contêm itens que se concentram na autorregulação precoce da criança, estimulação por objetos e interação face a face (por exemplo, se é bom para um bebê dormir sozinho).

b) Escala de Metas de Socialização: é também uma versão traduzida e adaptada para o português pelo núcleo de pesquisa anteriormente citado, de uma escala elaborada por Keller et al. (2006). A escala tipo Likert de cinco pontos (de $1=$ concordo nem um pouco até $5=$ concordo completamente) é formada pordez afirmativas para investigar crenças sobre o que uma criança deveria aprender ou desenvolver durantes os 3 primeiros anos de idade. Também é composta por duas dimensões:

- metasinterdependentes/relacionais, que incluem itens como "aprender a obedecer a pessoas mais velhas" e "aprender a animar os outros";

- metas independentes/autônomas, que incluem itens como "desenvolver auto- confiança" e "desenvolver um senso de autoestima".

c) Escala de Alocentrismo Familiar: também foi traduzida e adaptada para o português pelo núcleo de pesquisa anteriormente citado. O modelo original foi elaborado por Lay et al. (1998) e consiste em uma escala tipo Likert de cinco pontos $(1=$ concordo nem um pouco até $5=$ concordo completamente), contendo 21 itens com escores que indicam direção alocêntrica, com 6 itens invertidos ligados ao idiocentrismo. Alocentrismo e idiocentrismo são dimensões do conceito que uma pessoa tem de si mesma, do ponto de vista da psicologia cultural e refletem dependência ou separação da família ou do grupo social mais próximo, respectivamente, e são úteis para investigar variações culturais. A dimensão alocentrismo-idiocentrismo foi empregada pelos autores que elaboraram a escala com o significado de conexão ao grupo de origem.

d) Questionário de dados sócio-demográficos: teve como objetivo caracterizar a idade das mães, número de filhos, local de residência, configuração da família, escolaridade e renda familiar mensal.

\section{Procedimento}

O contato inicial com as mães foi feito por meio de postos de saúde, creches e centros de educação infantil. As mães participantes também colaboraram com a coleta, indicando outras mães conhecidas para a pesquisa. As entrevistas, com duração média de uma hora, eram agendadas em contato prévio com as mães, que escolhiam o local, a data e o horário de sua preferência.

Com relação aos cuidados éticos, a pesquisa foi aprovada pelo Conselho de Ética da Universidade Federal de Santa Catarina, protocolada sob o número 239/06, e as mães participantes do estudo assinaram um Termo de Consentimento Livre e Esclarecido, com todas as informações sobre a pesquisa, inclusive dados para contato com os pesquisadores. 
Westphal, J. P., Vieira, V., Vieira, M. L., Prado, A. B.

\section{Análise de dados}

Os dados obtidos nos três contextos foram analisados inicialmente em conjunto, com o objetivo de comparar as médias das práticas, metas e alocentrismo. Para isso foi utilizado o teste paramétrico Análise de Variância (ANOVA). Havendo diferença nessa primeira análise, o teste post hoc de Tukey foi utilizado para verificar em quais comparações entre os contextos dois a dois havia diferença (Dancey \& Reidy, 2006).

Os três contextos deste estudo também foram analisados separadamente. Primeiramente, foi analisado se a diferença entre as médias de cada instrumento era estatisticamente significativa, utilizando o teste t pareado - que mostra se as distinções entre as médias são significativas (Dancey \& Reidy, 2006). Após esse procedimento, foi realizado um cruzamento das características sócio-demográficas com as etnoteorias, com análise de correlações, por meio do qual o teste $\mathrm{r}$ de Pearson mostra o grau de relacionamento entre as variáveis e a probabilidade dessas relações ocorrerem por erro amostral (Dancey \& Reidy, 2006).

\section{Resultados}

As respostas das mães dentro de cada contexto e entre os contextos demonstraram diferenças estatisticamente significativas entre as médias dos instrumentos utilizados. A Tabela 1 mostra esses resultados através do teste t pareado.

Analisando-se as "práticas parentais", conforme pode ser visualizado na Tabela 1, constata-se que as mães do interior leste e do interior oeste valorizam significativamente mais a dimensão autônoma. Por outro lado, não houve diferença significativa entre as mães da capital nas dimensões autônoma e relacional. Na comparação entre os três contextos, constatou-se que houve diferença significativa entre eles. Por meio de análises de comparações múltiplas de contextos dois a dois, constatou-se que as mães do oeste realizam significativamente mais práticas autônomas que as da capital (DHS $=0,33 \mathrm{p}<0,05$ ). Por outro lado, não houve diferença significativa com relação às "práticas relacionais" entre os três contextos.

Tabela 1 - Média (£DP) das respostas das mães em relação aos instrumentos utilizados e os resultados das análises estatísticas

\begin{tabular}{llllc}
\hline & Capital & Interior leste & Interior oeste & F (2,14) \\
\hline Práticas parentais & & & & \\
Relacional & $3,28( \pm .85)$ & $3,13( \pm .83)$ & $3,39( \pm .89)$ & 1,15 \\
Autonomia & $3,54( \pm .86)$ & $3,86( \pm .67)$ & $3,92( \pm .56)$ & $4,24^{*}$ \\
t (50) & 1,84 & $5,59 *$ & $3,52^{*}$ & \\
Metas de Socialização & & & & \\
Relacional & $3,20( \pm .84)$ & $3,80( \pm .73)$ & $3,94( \pm .60)$ & $14,40^{* *}$ \\
Autonomia & $3,90( \pm .71)$ & $3,94( \pm .80)$ & $3,76( \pm .74)$ & 0,73 \\
t (50) & $5,02 * *$ & 1,17 & 1,47 & \\
Alocentrismo familiar & & & & \\
Alocêntrico & $3,37( \pm .61)$ & $3,80( \pm .52)$ & $3,83( \pm .46)$ & 0,63 \\
Idiocêntrico & $3,25( \pm .64)$ & $3,17( \pm .76)$ & $3,10( \pm .62)$ & \\
t (50) & 0,81 & $5,91 *$ & $6,81 * *$ & \\
\hline
\end{tabular}

Nota: ${ }^{*} \mathrm{p}<0,05 ;{ }^{*} \mathrm{p}<0,01$. 
Com relação à variável "metas de socialização", por meio da Tabela 1 constata-se que as mães da capital valorizam significativamente mais a dimensão autônoma do que a relacional. Por outro lado, tanto mães residentes no leste como no oeste do Estado de Santa Catarina não apresentaram diferenças significativas entre as médias da variável "metas de socialização". Já na comparação dos três contextos, constatou-se diferença entre eles. Pela comparação entre os contextos dois a dois, as mães da capital apresentaram significativamente menos a dimensão relacional que as residentes no leste $[(\mathrm{DHS}=0,60)$, $\mathrm{p}<0,05)]$ e com relação às mães da região oeste $[(\mathrm{DHS}=0,74), \mathrm{p}<0,05)]$. Entretanto, não houve diferença estatisticamente significante entre os três contextos na variável "metas autônomas".

No que se refere à escala de alocentrismo, por meio da Tabela 1 verifica-se que as mães da capital não apresentaram diferença estatisticamente significativa entre as dimensões alocêntrica e idiocêntrica. No interior leste e no interior oeste, a dimensão alocêntrica foi significativamente mais valorizada. Com relação à análise entre os três contextos, observou-se diferença significativa entre eles. $\mathrm{Na}$ análise de comparações múltiplas de contexto dois a dois, mães residentes na capital do Estado valorizam menos a dimensão alocêntrica do que mães residentes na região oeste $[(\mathrm{DHS}=0,46), \mathrm{p}<0,05)] \mathrm{e}$ também em comparação com as mães residentes na região leste $[(\mathrm{DHS}=0,43), \mathrm{p}<0,05)] . \mathrm{Na}$ dimensão idiocêntrica não foi encontrada nenhuma diferença estatisticamente significativa entre os três contextos.

Verificando-se as práticas parentais com dados sócio-demográficos, na capital houve uma correlação negativa entre a variável "práticas parentais" e as duas dimensões do instrumento, indicando que quanto maior a escolaridade, menor é a realização de práticas relacionais $(\mathrm{r}=0,29 ; \mathrm{p}<0,05) \mathrm{e}$ autônomas $(\mathrm{r}=0,35 ; \mathrm{p}<0,05)$. Aferiu-se também uma correlação significativa entre as dimensões da escala para as mães da capital: quanto mais realizam práticas relacionais, mais realizam práticas autônomas $(\mathrm{r}=0,32 ; \mathrm{p}<0,05)$, o que sugere a presença do modelo autônomo-relacional entre as mães urbanas. No interior, a correlação entre práticas e dados sócio-demográficos apontou que o número de filhos parece ser uma variável importante, uma vez que mães com maior número de filhos realizam mais práticas relacionais $(\mathrm{r}=0,31 ; \mathrm{p}<0,05)$. Já no interior oeste, as práticas relacionais apresentaram correlações com quatro variáveis sócio-demográficas: quanto maior o número de pessoas na casa, mais aparece a dimensão relacional $(\mathrm{r}=0,42 ; \mathrm{p}<0,01)$; quanto maior a escolaridade das mães do interior oeste, menos práticas relacionais eram apresentadas $(\mathrm{r}=0,54 ; \mathrm{p}<0,01)$; a dimensão relacional aparecia menos quanto maior a renda das mães $(r=0,71$; $\mathrm{p}<0,01)$; e, assim como no interior leste, um maior número de filhos está correlacionado com mais práticas relacionais $(\mathrm{r}=0,47 ; \mathrm{p}<0,01)$.

$\mathrm{Na}$ correlação entre a variável "metas de socialização" com dados sócio-demográficos, no contexto da capital, a escolaridade foi um fator bastante importante, assim como a renda familiar mensal. $\mathrm{O}$ número de pessoas que vivem na casa e o número de filhos também apresentaram valores significativos de correlação. Verificou-se que quanto maior a escolaridade $(\mathrm{r}=0,55 ; \mathrm{p}<0,01)$ e a renda $(\mathrm{r}=0,59 ; \mathrm{p}<0,01)$, menores as médias para metas relacionais; e quanto mais pessoas vivem na casa $(\mathrm{r}=0,343)$ e maior o número de filhos $(\mathrm{r}=0,32)$, menores as médias para metas autônomas ( $\mathrm{p}<0,05)$. No interior leste, a correlação das metas de socialização com dados sócio-demográficos não demonstrou resultados significativos. Somente as dimensões da escala de metas são correlacionadas entre si para a amostra residente no interior, indicando que quanto mais as mães valorizam metas autônomas, mais valorizam metas relacionais $(\mathrm{r}=0,47$; $\mathrm{p}<$ $0,01)$. Esse dado referente às metas de socialização das mães do interior também sugere a presença do modelo autônomo-relacional nesse contexto. Já no interior oeste, a variável "metas de socialização" se correlacionou negativamente com a escolaridade da respondente e a renda familiar mensal, indicando que quanto maior a escolaridade $(r=0,40 ; p<0,01)$ e a renda $(r=0,29 ; p<0,05)$, menos metas relacionais são realizadas. As "metas relacionais" do interior oeste também se correlacionaram positivamente com a variável "práticas relacionais" ( $\mathrm{r}=0,29 ; \mathrm{p}<0,05)$, indicando que quanto mais esta é realizada, mais a dimensão relacional aparece.

Nas correlações do "Alocentrismo" com dados sócio-demográficos, em nenhum dos três contextos foi encontrada uma relação estatisticamente significativa. Contudo, a escala de alocentrismo se relaciona com as outras escalas. $\mathrm{Na}$ capital, quanto maior a dimensão alocêntrica, mais metas relacionais são realizadas $(\mathrm{r}=0,42 ; \mathrm{p}<0,01)$, e quanto maior a dimensão idiocêntrica, mais metas autônomas 
são encontradas $(r=0,35 ; \mathrm{p}<0,05)$. Além disso, quanto mais a dimensão alocêntrica aparece, menos se valoriza a dimensão idiocêntrica $(r=0,29$; $\mathrm{p}<0,05)$. Já no interior leste, as "metas relacionais" se correlacionaram positivamente com ambas as dimensões da escala de alocentrismo (Alocêntrica $r=0,28$, Idiocêntrica $r=0,33, p<0,05)$. A escala se correlacionou - diferentemente da capital - positivamente entre si, sugerindo que quanto mais se realiza a dimensão alocêntrica, mais se realiza também a dimensão idiocêntrica ( $r=0,35, \mathrm{p}<0,05)$. No contexto do interior oeste, assim como no interior leste, as "metas relacionais" se correlacionaram positivamente com a dimensão alocêntrica $(r=0,29, \mathrm{p}<0,05)$ e com a idiocêntrica $(r=0,40, p<0,01)$, indicando novamente o modelo autônomo-relacional. A variável "práticas autônomas" foi correlacionada também no interior oeste com a dimensão alocêntrica, indicando que quando mais práticas autônomas são realizadas, mais se valoriza a dimensão alocêntrica $(\mathrm{r}=0,31, \mathrm{p}<0,05)$. No interior oeste, as variáveis da escala de alocentrismo não apresentaram significância estatística nas correlações com outras variáveis da pesquisa.

\section{Discussão e conclusáo}

A pesquisa realizada buscou investigar os modelos de parentalidade em diferentes culturas, compostos por características sócio-demográficas diferenciadas. A partir disso, buscou-se investigar práticas durante o primeiro ano de vida da criança e metas de socialização de mães, bem como o grau de alocentrismo familiar delas, em três contextos sócio-culturais sul-brasileiros. Como levantado na hipótese inicial, verificou-se com os resultados obtidos a presença de elementos do modelo autônomo-relacional em todos os locais estudados. Esse tipo de orientação cultural, como relatado anteriormente, engloba autonomia e relação, em que o selfé definido como autônomo quanto à sua ação, e relacional quanto à proximidade interpessoal (Kagitçibasi, 1996, 2005).

Nos três contextos estudados encontra-se o modelo autônomo-relacional. Contudo, existem algumas diferenças entre os contextos estudados. Por exemplo, no interior leste e oeste, as mães apresentam mais características relacionais, enquanto na capital as respostas das mães estão mais relacionadas com a dimensão autônoma, representadas por meio dos resultados nos três instrumentos e nas correlações com os dados sócio-demográficos.

Em termos de uma caracterização sóciodemográfica, verificou-se que as mães residentes na capital possuíam em média apenas um filho, eram significativamente mais velhas e tinham maior escolaridade que as mães do interior, dados que indicam a valorização do ensino e a postergação da formação de uma família e do nascimento do primeiro filho. Apesar de a renda familiar mensal das mães residentes na capital não ter sido significativamente maior que a das mães do interior, observando-se os valores de média e desvio padrão, pode-se verificar que a variação da renda no interior foi muito maior que na capital, onde os valores foram mais homogêneos e, portanto, mais altos. Essas características sócio-demográficas das mães da capital parecem indicar aspectos de um modelo cultural mais autônomo, descrito por Keller (2006), que consiste em sociedades industrializadas, com alto grau de escolaridade, reprodução tardia e baixo número de filhos.

No que se refere às metas de socialização que as mães da capital possuem a respeito de seus filhos, também foram encontrados aspectos mais autônomos, uma vez que as mães valorizaram significativamente mais as 'metas autônomas' do que as 'relacionais'. Pode-se pensar que esse desejo das mães que seus filhos desenvolvam cada vez mais cedo independência, autoconfiança, senso de identidade e autoestima esteja relacionado com algumas transformações que ocorreram na sociedade brasileira nos últimos anos, principalmente nas capitais e em contextos mais urbanos. Dentre essas mudanças, Dessen e Torres (2002) citam a globalização e a modernização, os novos padrões de consumo e a flexibilidade no mundo do trabalho. Para essas autoras, tais fatores macrossociais e históricos possivelmente modificaram as características das famílias brasileiras e consequentemente as ideias acerca do desenvolvimento da criança e a maneira de criar os filhos. Biasoli-Alves (2002) cita ainda alguns aspectos mais específicos, como o aumento da escolarização, a entrada cada vez mais precoce das crianças na escola, as alterações dos papéis femininos e masculinos, e a disseminação dos conhecimentos científicos como base para a orientação das relações interpessoais.

Nesse mesmo sentido, as correlações das dimensões estudadas com dados sócio-demográficos na capital indicaram que quanto maior a escolarização 
e renda familiar das mães, e quanto mais baixo o número de pessoas residentes no lar, maior o predomínio da dimensão autônoma da parentalidade. Outros estudos, realizados dentro e fora do Brasil, encontraram resultados semelhantes, principalmente no que se refere ao índice de escolaridade das mães, que é considerado variável chave para o estudo da parentalidade (Goodnow, 1988; Lordelo, Fonseca \& Araújo, 2000; Suizzo, 2002; Seidl de Moura et al. 2004, Kobarg, 2006; Piovanotti, 2007). No caso específico do Brasil, o aumento da escolarização é um fator que parece exercer grande influência na estrutura do cotidiano das pessoas, trazendo reflexos também na forma de criar e educar os filhos (Biasoli-Alves, 2002). Segundo dados do IBGE, entre os anos de 1991 e 2000 (IBGE, 2000), houve um aumento de $17,2 \%$ da população acima de 25 anos de idade que possuem curso superior completo (graduação, mestrado ou doutorado). Ainda, entre 1940 e 2000 verificou-se um aumento de $45 \%$ da população alfabetizada, ou seja, que sabe ler e escrever (IBGE, 2007).

Ainda na capital, em termos de práticas e alocentrismo familiar, foram verificados elementos do modelo autônomo-relacional. As mães valorizaram igualmente as 'práticas autônomas' e as 'relacionais', ou seja, atribuíram igual importância à realização de práticas que visem tanto ao desenvolvimento da independência desde cedo na criança, quanto da interdependência e autorregulação. Além disso, o grau de 'alocentrismo' e 'idiocentrismo' também não diferiu, o que indica que, ao mesmo tempo em que elas estão ligadas à sua família de origem, também conseguem manter certa distância e individualização. Esses dados se assemelham aos encontrados por Keller et al. (2006) em contextos autônomorelacionais como Beijing e Taiwan (China), São José (Costa Rica), Cidade do México (México) e Delhi (Índia). Os autores verificaram que tais contextos ocuparam uma posição intermediária em relação a contextos autônomos, de um lado, e relacionais, de outro. Além disso, em geral, nesses contextos também foram encontradas médias bastante semelhantes para as dimensões autônomo e relacional de cada instrumento investigado (Keller et al., 2006). Pode-se, então, pensar que a capital estudada na presente pesquisa seja caracterizada pelo modelo autônomo-relacional, mas com uma forte presença da dimensão autônoma, mais predominante que a relacional.

No interior leste, em termos de uma caracterização sócio-demográfica, verificou-se menor idade e escolaridade das mães, com uma variação mais expressiva da renda familiar mensal. O número de filhos não foi maior que o da capital, embora as mães sejam mais novas. Esperava-se, ao contrário, que elas tivessem mais filhos, o que indicaria uma estratégia reprodutiva quantitativa, característica de sociedades mais interdependentes, de acordo com Keller et al. (2006). Outra característica das mães do Interior Leste refere-se à sua origem étnica alemã, a qual é descrita na literatura como predominantemente autônoma e independente (Keller et al., 2004, 2005). Esses dados sociodemográficos das mães do interior, sendo elas mais novas, de escolaridade moderada, de origem étnica alemã, com formação mais precoce de uma família e do nascimento do primeiro filho e estratégia reprodutiva não tanto quantitativa, parecem indicar características tanto autônomas quanto relacionais, o que resultaria em um modelo mais autônomo-relacional.

Esses dados estão de acordo com os resultados de práticas, metas e alocentrismo, uma vez que também foi verificada a predominância do modelo autônomo-relacional, por meio da investigação de tais dimensões. Os dados obtidos em metas e alocentrismo evidenciaram a presença da dimensão relacional, enquanto os resultados de práticas indicaram aspectos mais autônomos nesse contexto. Em termos de metas, verificou-se que as mães valorizaram igualmente as dimensões autônoma e relacional, porém obtiveram médias significativamente maiores nas metas relacionais do que as mães da capital. Constatou-se também que as mães residentes no interior foram mais 'alocêntricas' do que 'idiocêntricas', ou seja, apresentaram-se predominantemente vinculadas à sua família de origem. Esse valor também foi superior ao obtido entre as mães da capital. A partir desses dados, pode-se sugerir que o interior caracteriza-se por ser um contexto em que há mais proximidade física entre as pessoas, sendo que também se espera dos filhos que eles desenvolvam essa capacidade de se relacionar bem com os outros, respeitando os pais e as pessoas mais velhas.

Já em termos de práticas, as mães do interior valorizaram mais a dimensão autônoma que a relacional. Esse resultado não era esperado, uma vez que se imaginava que também haveria um predomínio da dimensão relacional, assim como em metas e alocentrismo. Uma possível explicação para o que foi verificado, no entanto, seria o próprio conteúdo dos itens que compõem essa dimensão, que está 
relacionado com rotinas (dormir a noite toda, por exemplo), além da habilidade da criança de realizar determinados comportamentos por ela mesma (dormir, interagir com objetos e brinquedos, por exemplo). Tais aspectos provavelmente foram mais valorizados em função das necessidades das mães, que trabalham tanto fora quanto dentro de casa e precisam que os filhos tenham rotinas e brinquem mais sozinhos desde cedo.

No que diz respeito à caracterização sóciodemográfica, verificou-se que as mães residentes no interior oeste possuíam média de um ou dois filhos, idade média de 29 anos e tinham menor escolaridade, características que apontam para uma menor valorização do ensino, com maior ênfase nos afazeres domésticos, já que a maioria delas não trabalha fora de casa. A 'renda familiar mensal' foi a menor em comparação aos outros dois contextos, dado esse que pode ser atribuído ao fato de somente os pais trabalharem. Essas características sócio-demográficas das mães do interior oeste parecem indicar aspectos de um modelo de interdependência, no qual predominam as dimensões de heteronomia e relações características de ambientes rurais baseados em economia de subsistência (Keller et al., 2005).

Ainda com relação aos aspectos sóciodemográficos, verificou-se que o 'número de filhos' e a 'renda familiar' parecem ser variáveis importantes na modulação do fenômeno da parentalidade no interior. Quanto maior o número de filhos, maior a valorização de 'práticas relacionais'; enquanto que quanto menos renda, mais 'metas autônomas'. Pode-se pensar que quanto mais filhos, maior a necessidade das mães de garantir que os mesmos convivam em harmonia e proximidade, não sendo dada tanta ênfase ao individualismo e à estimulação da autonomia de cada um dos filhos.

No que se refere às práticas parentais, as mães residentes no interior oeste, em comparação com as que vivem na capital, apresentaram em suas respostas 'práticas autônomas' significativamente maiores. Já as 'práticas relacionais' foram igualmente valorizadas pelas mães dos três contextos. Esses dados podem ser explicados se considerarmos que a economia da cidade gira em torno da agropecuária e que, embora as mães não trabalhem formalmente, elas ajudam na agricultura, auxiliando no plantio e colheita, o que requer que as crianças aprendam desde cedo a ter, por exemplo, rotinas de sono e alimentação bem estabelecidas.
Quanto às metas de socialização, as respostas das mães do interior oeste não apresentaram características significativas entre as médias das metas autônomas e relacionais. Inclusive as 'metas autônomas' foram valorizadas igualmente nos três contextos do estudo. $\mathrm{Na}$ correlação de metas com dados sociodemográficos, quanto maior a escolaridade e a renda, menos 'metas relacionais' foram apontadas. Esses dados apresentam congruência com os resultados obtidos na correlação com práticas, ou seja, quanto maior a escolaridade e a renda, menos ‘práticas' e 'metas relacionais'.

No que diz respeito à escala de alocentrismo, no interior oeste a dimensão alocêntrica foi mais valorizada. Nesse contexto as pessoas possuem maior proximidade física e as mães são mais ligadas à sua família de origem. A variável 'práticas autônomas' foi correlacionada no contexto interior oeste com a dimensão alocêntrica, ou seja, quanto mais 'práticas autônomas' são realizadas, mais a se valoriza a dimensão alocêntrica. Isso indica que, por mais que as mães dêem atenção às 'práticas autônomas', elas mantêm a proximidade com a família de origem.

\section{Consideraçóes finais}

Acredita-se que os resultados encontrados nesse estudo podem auxiliar no delineamento de um modelo cultural de parentalidade no contexto brasileiro. Muito tem sido estudado a respeito desse tema, porém a primazia de estudos centra-se em contextos europeus e norte-americanos. Dessa forma, além de auxiliar no delineamento de um modelo cultural brasileiro, os dados obtidos podem também complementar a compreensão que a literatura já possui sobre como os pais criam seus filhos, que qualidades esperam que estes desenvolvam ao longo do seu crescimento e a relação disto com o grau de ligação dos pais com sua família de origem.

Um resultado relevante é a indicação de que o contexto sul-brasileiro, mais especificamente o Estado de Santa Catarina, caracteriza-se pelo predomínio de um modelo cultural autônomo-relacional, porém com diferenças e similaridades bastante significativas entre interior e capital. Pensando em um gradual, a capital estaria mais próxima do modelo autônomo, enquanto que o interior, mais ligado ao relacional. 
É importante também que fiquem evidenciadas algumas limitações da presente pesquisa, bem como sugestões para futuros estudos na área. Em relação ao método, sugere-se a realização de estudos que utilizem outras formas de abordagem às mães para investigação das dimensões de práticas e metas, como a entrevista aberta e a observação. É possível que, dessa forma, sejam acessadas outras variáveis que interferem no fenômeno da parentalidade, bem como seja possível realizar uma caracterização mais aprofundada.

\section{Referências}

Biasoli-Alves, Z. M. M. (2002). A questão da disciplina na prática de educação da criança, no Brasil, ao longo do século XX. Veritati, 2(2), 243-259.

Cole, M. (1998). Cultural psychology: A once and future discipline. Cambridge, MA: The Belknap Press of Harvard University Press.

Dancey, C. P., \& Reidy,J. (2006) Estatística sem matemática para psicologia usando spss para windows. Porto Alegre: Artmed.

Dessen, M. A., \& Torres, C. V. (2002). Family and socialization factors in Brazil: An overview. In W. J. Lonner, D. L. Dinnel, S. A. Hayes, \& D. N. Sattler (Ed.). Online Readings in Psychology and Culture (Unit 13, Chapter 2). Recuperado em 15 mar. 2008, em http:/ / www.ac.wwu.edu/ culture/DennenTorres.htm.

Goodnow,J.J. (1988). Parents' ideas, actions, and feelings: Models and methods from developmental and social psychology. Child Development, 59(2), 286-320.

Goodnow, J., \& Collins, W. A. (1990). Development according to parents: The nature, sources, and consequences of parents' ideas. Hove: Erlbaum.

Harkness, S., \& Super, C. M. (1996). Parents' cultural beliefs systems: Their origins expressions, and consequences. New York: The Guilford Press.

Harkness, S., Super, C. M., Axia V., Eliasz, A., Palacios, J., \& Welles-Nyström, B. (2001). Cultural pathways to successful parenting. International Society for the Study of Behavior Development Newsletter, 1(38), 9-13.

Instituto Brasileiro de Geografia e Estatística - IBGE. (2006). Cidades. Recuperado em 8 mar. 2008, em http://www.ibge.gov.br
Instituto Brasileiro de Geografia e Estatística - IBGE. (2007). Estatísticas do século XX. Recuperado em 8 mar. 2008, em http://www.ibge.gov.br

Kagitçibasi, C. (1996). The autonomous-relational self: A new synthesis. European Psychologist, 1(3), 180-186.

Kagitçibasi, C. (2005). Autonomy and relatedness in cultural context: Implications for self and family. Journal of Cross-Cultural Psychology, 36(4), 403-422.

Keller, H., Hentschel, E., Yovsi, R. D., Lamm, B., Abels, M., \& Haas, V. (2004). The psycho-linguistic embodiment of parental ethnotheories: A new avenue to understanding cultural processes in parental reasoning. Culture and Psychology, 10(3), 293-330.

Keller, H., Borke, J., Yovsi, R., Lohaus, A., \& Jensen, H. (2005). Cultural orientations and historical changes as predictions of parenting behavior. International Journal of Behavioral Development, 29(3), 229-237.

Keller, H.,Lamm, B., Abels, M., Yovsi, R., Borke,J.,Jensen, H., et al. (2006). Cultural models, socialization goals, and parenting ethnotheories: A multicultural analysis. Journal of Cross-Cultural Psychology, 37(2), 155-172.

Kobarg, A. P. (2006). Crenças e práticas de mães sobre o desenvolvimento infantil nos contextos rural e urbano. Dissertação de Mestrado em Psicologia apresentada ao Programa de Pós-Graduação em Psicologia na Universidade Federal de Santa Catarina, Florianópolis.

Lay, C., Fairlie, P., Jackson, S., Ricci, T., Eisenberg, J., Sato, T. et al. (1998). Domain-specific allocentrismidiocentrism. Journal of Cross-Cultural Psychology, 29(3), 434-460.

Lordelo, E. R., Fonseca, A. L., \& Araújo, M. L. V. B. (2000). Responsividade do ambiente de desenvolvimento: crenças e práticas como sistema cultural de criação de filhos. Psicologia Reflexão e Crítica, 13(1), 73-80.

Piovanotti, M. R. (2007). Metas de socialização infantil e crenças sobre práticas de cuidador parental de mães primíparas. Dissertação de Mestrado em Psicologia apresentada ao Programa de Pós-Graduação em Psicologia na Universidade Federal de Santa Catarina, Florianópolis.

Ribas, R. C. Jr., Seidl de Moura, M. L., \& Bornstein, M. C. (2003). Socioeconomic status in Brazilian psychological research: I. Validity, measurement and application. Estudos de Psicologia, 8(3), 375-383. 
Ruela, S. F. (2006). Um estudo intergeracional de crenças valorizadas por mães em uma comunidade rural do Estado do Rio de Janeiro. Dissertação de Mestrado em Psicologia apresentada no Programa de Pós-Graduação em Psicologia Social da Universidade Estadual do Rio de Janeiro, Rio de Janeiro.

Ruela, S. F., \& Seidl de Moura, M. L. (2007). Um estudo do nicho de desenvolvimento de um grupo de crianças em uma comunidade rural. Psicologia em Estudo, 12(2), 315-324.

Santa Catarina. (2006). Governo do Estado de Santa Catarina. Municípios. Recuperado em 8 mar. 2008, em http://www.sc.gov/conteudo/municipios

Seidl de Moura, M. L., Ribas, R. C. Jr., Piccinini, C. A., Bastos, A. C. S., Magalhães, C. M. C., Vieira, M. L., et al. (2004). Conhecimento sobre desenvolvimento infantil em mães primíparas de diferentes centros urbanos do Brasil. Estudos de Psicologia, 9(3), 421-429.

Suizzo, M. A. (2002). French parents' cultural models and childrearing beliefs. International Journal of Behavioral Development, 26(4), 297-307.

Vieira, M. L., \& Prado, A. B. (2004) Abordagem evolucionista sobre a relação entre filogênese e ontogênese no desenvolvimento infantil. In Maria Lúcia Seidl de Moura. (Ed.). O bebê do século XXI e a psicologia em desenvolvimento (pp. 155-203). São Paulo: Casa do Psicólogo.

Recebido: 30/06/2008

Received: 06/30/2008

Aprovado: 30/10/2009

Approved: 10/30/2009 